\title{
Who lives where? Molecular and morphometric analyses clarify which Unio species (Unionida, Mollusca) inhabit the southwestern Palearctic
}

\author{
Elsa Froufe $^{1}$ • Duarte V. Gonçalves ${ }^{2,3,4}$ - Amílcar Teixeira ${ }^{5}$. Ronaldo Sousa ${ }^{1,6}$ • \\ Simone Varandas ${ }^{7} \cdot$ Mohamed Ghamizi $^{8} \cdot$ Alexandra Zieritz $^{9} \cdot$ Manuel Lopes-Lima $^{1}$
}

Received: 21 October 2015 / Accepted: 3 January 2016/Published online: 19 January 2016

(C) Gesellschaft für Biologische Systematik 2016

\begin{abstract}
Many doubts still exist about which freshwater mussel Unio species inhabit Northwest Africa. While some authors refer to the presence of Unio delphinus in the Atlantic North African basins of Morocco, a recent International Union for Conservation of Nature (IUCN) assessment performed on Moroccan Unio species, recognised the existence of a distinct species, Unio foucauldianus, with a critically endangered conservation status. The present study delivered new genetic, morphological, and geographical distribution data on two Unio species (i.e. U. delphinus and U. foucauldianus) greatly increasing the almost non-existent data on these taxa. Bayesian phylogenetic analysis revealed two highly supported geographically concordant clades, which diverged by $3.2 \pm 0.6 \%$ (uncorrected $p$ distance): the
\end{abstract}

Electronic supplementary material The online version of this article (doi:10.1007/s13127-016-0262-x) contains supplementary material, which is available to authorized users.

Elsa Froufe

elsafroufe@gmail.com

1 CIIMAR/CIMAR-Interdisciplinary Centre of Marine and Environmental Research, University of Porto, Rua dos Bragas 289, 4050-123 Porto, Portugal

2 CIBIO/InBIO-Centro de Investigação em Biodiversidade e Recursos Genéticos da Universidade do Porto, R. Padre Armando Quintas, 4485-661 Vairão, Portugal

3 Departamento de Biologia da Faculdade de Ciências da Universidade do Porto, Rua Campo Alegre, 4169-007 Porto, Portugal

4 Institute of Evolutionary Biology (CSIC-Universitat Pompeu Fabra), Passeig Marítim de la Barceloneta 37-49, 08003 Barcelona, Spain first distributed across Iberia and corresponding to $U$. delphinus, and the second distributed across Morocco, corresponding to $U$. foucauldianus. These results were corroborated by the analysis of ten newly developed microsatellite loci as well as shell morphometry. We suggest that the IUCN critically endangered conservation status of $U$. foucauldianus should be revised and probably down-listed since its actual distribution is much wider than previously described. Phylogenetic relationships with the other Unio species were resolved, showing that $U$. delphinus and $U$. foucauldianus fall inside the pictorum lineage. The estimated molecular rate reported herein $(0.265 \pm 0.06 \%$ per million years) represents the first for the Unionida and could be used as a reference in future studies.
5 CIMO-ESA-IPB-Mountain Research Centre, School of Agriculture, Polytechnic Institute of Bragança, Campus de Santa Apolónia, Apartado 1172, 5301-854 Bragança, Portugal

6 CBMA-Centre of Molecular and Environmental Biology, Department of Biology, University of Minho, Campus de Gualtar, Braga, Portugal

7 CITAB-UTAD-Centre for Research and Technology of Agro-Environment and Biological Sciences, Forestry Department, University of Trás-os-Montes and Alto Douro, Apartado 1013, 5001-811 Vila Real, Portugal

8 Muséum d'Histoire Naturelle de Marrakech, Faculté des Sciences, Université Cadi Ayyad, SemlaliaB.P. 2390Marrakech, Morocco

9 School of Geography, University of Nottingham Malaysia Campus, Jalan Broga 43500, Semenyih, Malaysia 
Keywords Freshwater molluscs · Unionidae . Microsatellites $\cdot$ Messinian $\cdot$ Molecular clock

\section{Introduction}

Freshwater mussels (Unionida) are among the most threatened fauna, globally in decline (Strayer 2008), and particularly vulnerable to habitat loss and fragmentation, changes in flow regimes, pollution, climatic disturbances and introduction of invasive species (Strayer et al. 2004). Despite their endangered status and well-recognised ecological importance, unionoid conservation is often impaired due to a lack of information and knowledge in many fields including ecology, physiology and genetics (Lopes-Lima et al. 2014). This includes a lack of a basic understanding of intraspecific genetic structure of most Unionida species (but see Froufe et al. 2014 and Lopes-Lima et al. 2016a, for recent European examples), as well as unresolved phylogenetic relationships between unionoid taxa (Lopes-Lima et al. 2016b). To a large part, this is due to the high phenotypic plasticity within unionoid species, rendering traditional conchological characters of limited use for identifying taxonomic units (Ortmann 1912; Zieritz and Aldridge 2009; Zieritz et al. 2010) and making species definitions in freshwater mussels a persistent and contentious problem. The emergence of genetic tools to detect evolutionary significant lineages has therefore led to broad taxonomic revisions in bivalves (Plazzi and Passamonti 2010).

The genus Unio is particularly notorious for its extreme intraspecific phenotypic plasticity and regional variations in shell shape. Up to the twentieth century, $>1000$ described species were included within the genus (Graf 2007). Haas (1969) considered this genus as a series of 12 'fundamental' Unio species, each comprising different 'races' or incipient species, mostly based on conchology. Recent molecular works have updated the taxonomy of the genus, which resulted in 13 currently recognised extant Unio species (Graf and Cummings 2015). Phylogenetically, Unio belongs to the largest freshwater bivalve family, the Unionidae, accounting for 674 out of 840 species ( $80 \%$ ) of the order Unionida (Graf and Cummings 2007). The phylogeny of this genus encompasses four main lineages: the pictorum, crassus, tumidus and gibbus lineage (Lopes-Lima et al. 2016b). Over the last decade, the pictorum lineage was divided into six species: Unio pictorum (Linnaeus 1758), Unio mancus Lamarck 1819, Unio delphinus Spengler 1793, Unio ravoisieri Deshayes 1848, Unio elongatulus Pfeiffer 1825 and Unio caffer Krauss 1848 (Van Damme 1984; Appleton 1996; Araujo et al. 2005; Khalloufi et al. 2011; Prié et al. 2012; Reis et al. 2013; Prié and Puillandre 2014).

While there are still uncertainties about the taxonomic status of the Unio species within this lineage in many regions, here we present the current evaluation of their geographical distributions. U. pictorum is the most widely distributed species, occurring from the UK extending South to Greece and Turkey and East to Russia (Van Damme 2011), while U. elongatulus is only present in Northern Italy and Croatia (Riccardi et al. 2016) and U. caffer is restricted to river systems across southern Africa (Kristensen et al. 2010). U. delphinus is present in most Western Iberian basins (Araujo et al. 2009a). $U$. ravoisieri is confined to two locations (one small basin and a small lake) in Spain (Araujo et al. 2009a) and Northwest Africa (Khalloufi et al. 2011). U. mancus is restricted to Mediterranean basins, from Eastern Iberia (Araujo et al. 2005) through France and Italy to the South-Eastern European countries (Haas 1969; Cuttelod et al. 2011).

Many doubts still exist about which Unio species inhabit Northwest Africa. Although Araujo et al. (2009a) refer to the presence of $U$. delphinus in both Iberia and North Africa, a subsequent IUCN assessment of the species restricted its occurrence to the Iberia Peninsula (Araujo 2011a). However, the assumption that this species is widespread in Atlantic Morocco, launched by Araujo et al. (2009a), has since become widely accepted (see, e.g. Morais et al. 2013; Machordom et al. 2015). Araujo et al. (2009a) also recognised the presence of Unio gibbus Spengler 1793 in the Atlantic North African basins of Morocco. On the other hand, recent IUCN assessments recognised the existence of $U$. gibbus and a distinct species, Unio foucauldianus Pallary 1936 in Morocco (Van Damme and Ghamizi 2010; Araujo 2011c). The taxonomic status and the presence of $U$. gibbus have already been confirmed for Morocco, Tunisia and Southern Iberia (Araujo et al. 2009b; Khalloufi and Boumaïza 2009; Khalloufi et al. 2011). Therefore, the present study will focus on clarifying which Unio species (i.e. U. delphinus, U. foucauldianus or both) inhabit Moroccan Atlantic rivers.

Numerous phylogeographic studies have confirmed the great importance of both Iberia and the Northwest African region (i.e. the Maghreb) as glacial refugia during the Pleistocene (Gómez and Lunt 2007; Husemann et al. 2012). Although there have been several studies using molecular tools on European invertebrates, few have included freshwater mussels from Iberia and even less from North Africa (but see Araujo et al. 2005, 2009a, b; Khalloufi et al. 2011; Reis et al. 2013; Froufe et al. 2014; Lopes-Lima et al. 2016a). After a land connection established around 5.96 Mya, the reopening of the Strait of Gibraltar around 5.33 Mya (Krijgsman et al. 1999) constituted a major vicariant event for many terrestrial and aquatic species. Since then, some secondary contact events took place, and at present, there is a high variety of colonisation patterns described across the Strait for different organisms. These patterns range from similar genetic lineages between northern Maghreb populations and those from Iberia (e.g. Schmitt et al. 2006; Carranza et al. 2006; Gaubert et al. 2010) to strong genetic splits (e.g. Steinfartz et al. 2000; García-París et al. 2003; Fonseca et al. 2009; Miraldo et al. 
2011). Some of these studies concluded that several taxa were able to cross the Strait during the Pleistocene, restricting the use of the Messinian Salinity Crisis (MSC) as a time calibration event. Therefore, many dated phylogenies of taxa occurring across the Strait are based on external substitution rates. However, the fact remains that for many taxa, especially those with low dispersal ability, the separation between Iberia and Africa is an effective barrier, and with proper caution, the MSC could be an informative biogeographical calibration point.

Studies that investigated molecular rates in Unionida to date have been based on substitution rates from distant (marine) bivalve taxa, calibrated with the age of the Panama Isthmus (e.g. Marko 2002) or other events (e.g. Luttikhuizen et al. 2003). Due to the huge differences in the molecular clock rates among species (Li 1997), these obtained divergence times might not be accurate, and a more reliable molecular clock should be estimated within the Unionida.

In this study, we aim to resolve the phylogenetic relationships within the $U$. pictorum lineage, as well as the distribution of species in Iberia and Maghreb, and the role of the MSC as a vicariant event. For that purpose, we combine molecular and morphological analyses in order to (i) characterise the genetic diversity patterns across the entire distribution of $U$. delphinus/ U. foucauldianus using mitochondrial DNA (mtDNA) sequences; (ii) characterise shell morphology patterns; and (iii) characterise the population structure in Iberia and Maghreb using microsatellites. Additionally, we hope to provide valuable insights for the conservation of these species, as well as more adequate calibration tools for molecular rates in Unionida.

\section{Materials and methods}

\section{Sample collection}

U. delphinus/U. foucauldianus specimens were collected from 21 sites across their reported distribution, spanning the major Atlantic basins in Iberia and Morocco (Araujo et al. 2009a; Van Damme and Ghamizi 2010) (Fig. 1; Table S1). A small sample from the foot was collected in the field (following Naimo et al. 1998) and placed directly into $99 \%$ ethanol for subsequent molecular analysis. Each specimen was additionally photographed for subsequent morphometric analysis and then returned to its original habitat. Genomic DNA was extracted from tissue samples using a standard high-salt protocol (Sambrook et al. 1989).

\section{Sequencing, alignment, phylogenetic and demographic analyses}

The F-type COI gene (ca. 700 bp fragment) was amplified for 74 U. delphinus/foucauldianus, 1 U. elongatulus and 1
U. mancus specimens applying LCO_22me and HCO_700dy primers (Walker et al. 2006, 2007), annealing temperature of $50{ }^{\circ} \mathrm{C}$ and other polymerase chain reaction (PCR) conditions as described in Froufe et al. (2014). Sequences were obtained using the BigDye sequencing protocol (Applied Biosystems 3730xl) by Macrogen Inc., Korea. One additional sequence (EF571434) was downloaded from GenBank to increase Pop 10 sample size (Table S1). Forward and reverse sequences were edited and assembled using ChromasPro 1.7.4 (Technelysium, Tewantin, Australia), and all sequences were then aligned with ClustalW, in Bioedit 7.2.5 (Hall 1999).

Unionida exhibit a peculiar mode of mitochondrial DNA transmission, known as doubly uniparental inheritance (DUI) of mitochondrial DNA (Zouros et al. 1994a, b; Hoeh et al. 1996; Liu et al. 1996). As a result, the nucleotide divergence between female and male mitochondrial genomes of the same species in the family Unionidae is no less than $40 \%$ (e.g. Breton et al. 2007; Huang et al. 2013; Froufe et al. 2016). In the present study, this value was used as a reference to assure that obtained COI sequences were indeed all F-type.

The best-fit model of nucleotide substitution under corrected Akaike Information Criterion was selected using JModelTest 2.1.7 (Posada 2008) for each partition, corresponding to each codon position. Model GTR was chosen for the first and third positions and F81 for the second. Phylogenetic inference was performed in MrBayes v.3.2.5 (Ronquist et al. 2012). Analyses started with programmegenerated trees and four heated Markov chains with default incremental heating. Two independent runs of $24 \times 10^{6}$ generations were sampled at intervals of 1000 generations producing a total of 24,000 trees. Burnin was determined upon convergence of log likelihood and parameter values, using Tracer 1.6 (Rambaut et al. 2014).

In order to resolve the phylogenetic relationships within the pictorum lineage, additional COI sequences from 14 specimens from the six described species of this lineage (available on GenBank; Table S2) were analysed together with six newly sequenced individuals, i.e. three from Iberia and three from Morocco, and two outgroup taxa following the same methodology as described above (with the exception of the models used, i.e. 1st HKY and 3rd GTR +I).

Haplotypes were deposited in GenBank (Table S1), and haplotype networks were calculated using TCS 1.21 (Clement et al. 2000) with a threshold of $95 \%$. Sequence divergences (uncorrected $p$ distance) were assessed using MEGA 6.0 (Tamura et al. 2013). Sequence and nucleotide diversity measures were calculated using DnaSP v.5.1.0.1. In order to examine the demographic history of the species and hypothesise post-Pleistocene range expansions, two neutrality tests were applied: Tajima D test, and Fu's Fs test. The first uses information on the mutation frequencies, while the latter uses information on the distribution of haplotypes (RamosOnsins and Rozas 2002). 


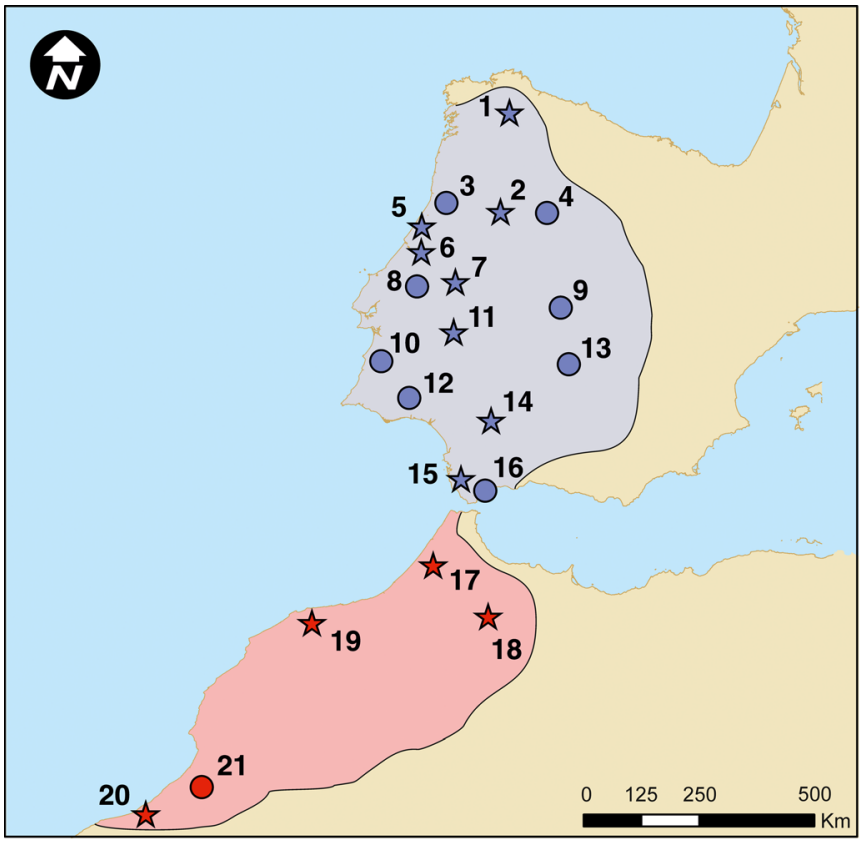

Fig. 1 Left, map showing the location of Unio delphinus (blue symbols) and Unio foucauldianus (red symbols) populations from Iberia and Morocco, respectively, included in the present study (Table S1, Supporting information). Blue and red areas represent the current known distribution of the two species. Circles indicate populations for which COI mtDNA sequences were analysed; stars indicate populations for which both mtDNA and microsatellites were analysed. Population code numbers follow Table S1 (Supporting information). Middle,

\section{Shell morphometry}

For a detailed analysis of inter- and intraspecific variation in shell morphometry of $U$. delphinus/foucauldianus (see 'Results'), we used Fourier shape analysis, as developed and explained by Crampton and Haines (1996). This method decomposes $x y$-coordinates of a shell outline into a number of harmonics, each of which is in turn explained by two Fourier coefficients. $x y$-coordinates of the sagittal shell outline of each specimen (20 specimens per population) were obtained from digital photographs using the programme IMAGEJ (Rasband 2008) and subjected to fast Fourier transformation using the programme HANGLE, applying a smoothing normalisation of 20 to eliminate high-frequency pixel noise. Preliminary analysis indicated that the first 10 harmonics described the outlines with sufficiently high precision. Discarding of the first harmonic, which does not contain any shape information, resulted in a set of 18 Fourier coefficients per individual. After rotating outlines to maximum overlap by programme HMATCH, principal component analysis (PCA) was performed on the 18 Fourier coefficients using programme PAST (Hammer and Harper 2006). The number of principal components to be retained was determined using the broken stick model of the scree plot. Synthetic outlines of extreme and average shell shapes were drawn using programme HCURVE as explained in Crampton and Haines (1996).

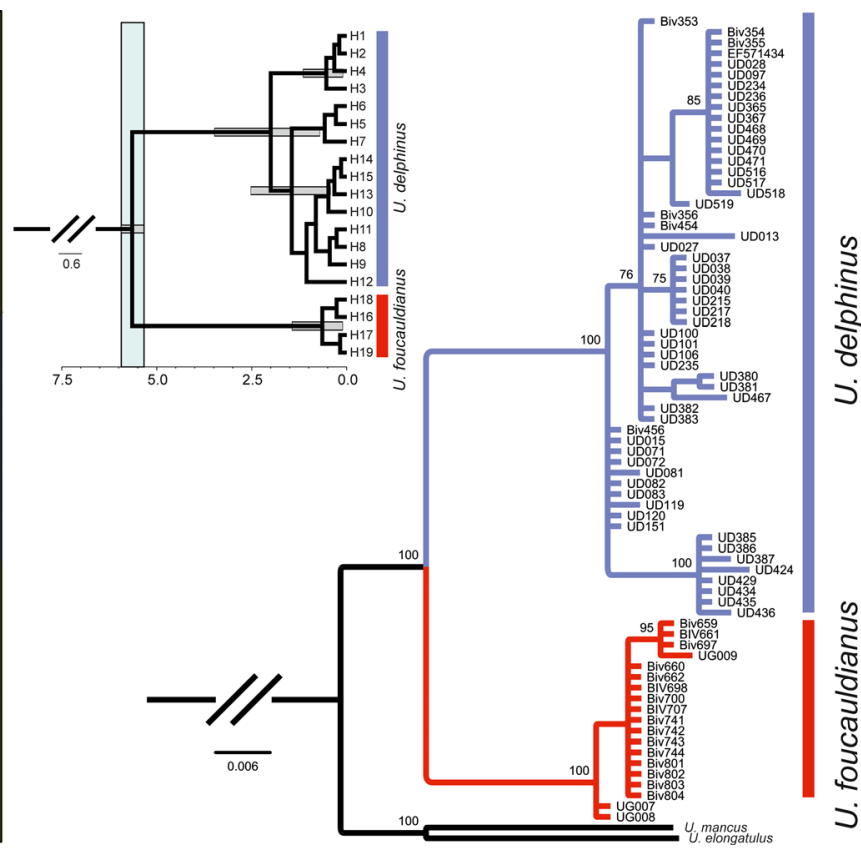

BEAST maximum clade credibility tree for $U$. delphinus and $U$. foucauldianus. Divergence time estimates are in million years. The grey bars indicate the height $95 \%$ HPD interval. The light-blue rectangle represents the MSC. Right, phylogenetic tree obtained by Bayesian Inference analysis of $77 \mathrm{mtDNA}$ COI sequences (633 bp) of $U$. delphinus and $U$. foucauldianus, with $U$. elongatulus and $U$. mancus as outgroups. Support values (\%) are given as Bayesian posterior probability above nodes

To test for statistically significant differences in sagittal shell shape between species and populations, analyses of variance (ANOVA) were run on all significant principal components, separately fitting species and population as a factor with two and ten levels, respectively. Tukey's post hoc test was performed to identify significant differences between each population pair. Finally, we assessed the rate of accurate species identification based on Fourier shape analysis using discriminant function analysis (DFA). Statistical analyses were performed in R.3.1.1.

\section{Microsatellite development and analyses}

Total genomic DNA from one $U$. delphinus individual collected in the Douro basin (Portugal; Pop 2, Fig. 1; Table S1) was sent to Genoscreen (Lille, France) for microsatellite-enriched library preparation and sequencing by 454 Genome Sequencer FLX Titanium (454, Roche Applied Science) using the method of Malausa et al. (2011).

PCR reactions were optimised following Froufe et al. (2013): three sets of ten primer pairs each were chosen and initially tested on 52 individuals (four per population) with PCR reactions in simplex to validate selected loci and ascertain optimal annealing temperatures. After these trials, ten loci were selected, combined in two multiplex-PCR reactions (eight in MixA and two in MixB) and tested for 
polymorphism in all the $153 \mathrm{U}$. delphinus individuals from eight populations collected in Iberia. PCR reactions were performed on a DNA Engine DyadW Peltier Thermal Cycler (Bio-Rad Laboratories), consisting of a denaturing step at $95{ }^{\circ} \mathrm{C}$ for $15 \mathrm{~min}$ followed by 9 cycles (11 for MixB) of denaturation at $95{ }^{\circ} \mathrm{C}$ for $30 \mathrm{~s}, 90 \mathrm{~s}$ annealing at $56{ }^{\circ} \mathrm{C}$ $\left(60{ }^{\circ} \mathrm{C}\right.$ for MixB) where the annealing temperature was lowered by $0.5^{\circ} \mathrm{C}$ with each consecutive cycle and $30 \mathrm{~s}$ elongation at $72{ }^{\circ} \mathrm{C} ; 31$ cycles ( 29 for MixB) of denaturation at $95{ }^{\circ} \mathrm{C}$ for $30 \mathrm{~s}$, annealing at $52^{\circ} \mathrm{C}\left(55^{\circ} \mathrm{C}\right.$ for MixB) for $60 \mathrm{~s}$ and extension at $72{ }^{\circ} \mathrm{C}$ for $30 \mathrm{~s}$; and a final extension at $60^{\circ} \mathrm{C}$ for $30 \mathrm{~min}$. Labelled PCR amplicons were resuspended in $10 \mathrm{~mL}$ Hi-DiTM Formamide and their sizes determined in an Applied Biosystems 3100 DNA analyser, with LIZ 500 as an internal size standard. The same loci were tested (using the same conditions) on a subset of 20 individuals collected from Morocco, i.e. from U. foucauldianus (see Results). As the loci amplified well in these individuals, the remaining 78 specimens collected from the four Morocco populations were scored for the same loci (using the same conditions).

In total, 231 individuals (12 populations) were genotyped for all the 10 loci. Genetix v.4.0.5.2 (Belkhir et al. 2004) was used to estimate allele frequencies, observed $\left(H_{\mathrm{O}}\right)$ and expected $\left(H_{\mathrm{E}}\right)$ heterozygosity. Linkage disequilibrium $(\mathrm{LD})$, inbreeding coefficients $\left(F_{\mathrm{IS}}\right)$, and deviations from the HardyWeinberg equilibrium (HWE) were tested in Genepop-onthe-Web (http://genepop.curtin.edu.au/index.html; Raymond and Rousset 1995) using exact tests with significance estimated by a Markov chain method after 10,000 randomizations and sequential Bonferroni correction employed to account for multiple testing (Holm 1979). The presence and frequency of null alleles were tested in each locus using MICROCHECKER (Van Oosterhout et al. 2004) and FREENA (Chapuis and Estoup 2007), respectively.

Global and single-locus genetic differentiation among samples and their putative genetic structuring were assessed with the $F_{\mathrm{ST}}$ fixation index (Weir and Cockerham 1984) in FSTAT 2.9.3.2 (Goudet 1995) with significance being assessed with 1.000 permutations. The impact of null alleles on $F_{\mathrm{ST}}$ estimation was assessed by comparing $F_{\mathrm{ST}}$ values before and after correction for null alleles using the excluding null alleles (ENA) method implemented in FREENA. As null alleles were found to have a minimal or no impact on $F_{\mathrm{ST}}$ estimates, all subsequent analyses were conducted on data uncorrected for null alleles.

Population structure was also analysed using the Bayesian model-based clustering approach implemented in STRUCTURE v.2.3.3 (Pritchard et al. 2000). Correlated allele frequencies, an admixture model without prior population information for individuals, was assumed. Fifteen independent runs were made for $K=1-13$ for the complete dataset (i.e. for the 12 populations) with each run consisting of a burn-in of $10^{5}$
Markov chain Monte Carlo steps, followed by $5 \times 10^{5}$ steps. Additionally, 15 independent runs were performed for $K=1-9$ for the $U$. delphinus dataset (i.e. for the eight Iberian populations) and for $K=1-5$ for $U$. foucauldianus (i.e. for the four Moroccan populations), with each run consisting on the same procedure as described above. Selection of the most likely number of genetic clusters $(K)$ was based on the second order rate of change in probability between successive $K$ values as described in Evanno et al. (2005) and implemented in STRUCTURE HARVESTER (Earl and von Holdt 2012).

Recent bottleneck events were explored using the method of Luikart et al. (1998), as implemented in BOTTLENECK v.1.2.02 (Piry et al. 1999). BOTTLENECK was run under the two-phase mutation model (TPM), which incorporates elements of both the stepwise mutation (SMM) and the infinite allele model (IAM) and is considered to provide the best fit for most microsatellite loci (Di Rienzo et al. 1994). Parameters included a proportion of SMMset at $70 \%$ and a default variance of 30 among multiple steps. Significance was assessed using Wilcoxon signed-rank tests with 10,000 iterations.

\section{Divergence time estimates}

Divergence times among lineages were estimated for COI sequences using Beast v.1.8.2 (Drummond and Rambaut 2007), using the connection between North Africa and Iberia to constrain the root age of the tree (5.33-5.96 Mya, Krijgsman et al. 1999). A haplotype alignment was used to reduce computational load and improve visualisation of the results. The dataset was run under a HKY $+\mathrm{I}$ substitution model according to jModelTest results. Sequence evolution was assumed to follow an uncorrelated lognormal relaxed clock (Drummond et al. 2006), and BEAST allowed to estimate the clock rate under a uniform distribution, which being a weak prior did not significantly distort the biogeographical calibration. The tree prior was set to constant size coalescent (Kingman 1982), given most of the sampled relationships are at the intraspecific level, and the tree root height was constrained to the 5.33-5.96 Mya interval using a lognormal prior with a one-sided cutoff at 5.33 Mya. A lognormal prior places a higher probability density closer to present, which we think best fits the data since the Mediterranean was only totally isolated from the Atlantic from 5.59 to 5.33 Mya (Krijgsman et al. 1999). Other parameters used default settings. The analysis was run for $10^{7}$ generations, sampling every 1000 generations. Quality of the runs and parameter convergence were assessed using Tracer v.1.6 (Rambaut et al. 2014). The maximum credibility tree of mean heights was then constructed using TreeAnnotator and discarding 300 trees as burn-in. 


\section{Results}

\section{mtDNA sequencing}

All mtDNA COI sequences obtained were considered Ftype, as no sequences similar to the M-type were detected. Sequences spanning 633 bp were obtained (36 polymorphic and 26 parsimony informative sites) for all individuals. No insertions or deletions, and no stop codons were observed after translating all sequences to amino acids.

The results of the Bayesian phylogenetic analysis are shown in Fig. 1. Two highly supported geographically concordant clades were retrieved, which diverged by $3.2 \pm 0.6 \%$ (uncorrected $p$ distance): the first clade was distributed across Iberia and corresponded to $U$. delphinus (56 specimens), and the second clade was distributed across Morocco and corresponded to $U$. foucauldianus (19 specimens). The southernmost Iberian basins Guadalquivir, Barbate and Guadiaro form a geographically coherent monophyletic group (pop 14-16; Table S1; Fig. 1). On the other hand, sub-clades within the $U$. foucauldianus were not geographically concordant. Time calibration showed a substitution rate for COI of 0.265 $\pm 0.06 \%$ /million years and that the most recent common ancestor (MRCA) of the extant lineages of $U$. delphinus is much older than the MRCA of $U$. foucauldianus (Fig. 1). High levels of nucleotide variability were detected in $U$. delphinus when compared with $U$. foucauldianus as shown in Table 1. Tests of demographic history yielded significantly negative results $(p<0.05)$ only for Fs (Fu's) statistics for $U$. delphinus (Table 1), although the value for the D (Tajima's) test was also negative. As for $U$. foucauldianus, no significant results were retrieved (Table 1). The summary of the indices of genetic diversity estimated for each population of both species is shown in Table 2.

The 56 sequences obtained from $U$. delphinus were collapsed to 15 unique haplotypes and linked with 14 mutations to the four haplotypes retrieved from the 19 U. foucauldianus individuals sequenced (Fig. 2). The haplotype networks revealed that no particular geographic structure of genetic variability was found, except for the four haplotypes retrieved from the most Southern Iberian basins (Guadalquivir, Barbate and Guadiaro), which are separated by three mutations (Fig. 2).

Phylogenetic analysis of COI sequences from six newly sequenced individuals, i.e. three from Iberia (=U. delphinus) and three from Morocco (=U. foucauldianus), fourteen specimens of the six described species of the pictorum lineage and two outgroups revealed that $U$. delphinus and $U$. foucauldianus fall inside the pictorum lineage (Fig. 3). The genetic distances between other pairs of Unio sp. are presented in both Fig. 3 and in more detail in Table 3.

\section{Shell morphometry}

The first two principal components obtained by PCA on the 18 Fourier coefficients were retained by the broken stick model and together explained $42.5 \%$ of the total variance in sagittal shell shape (Fig. 4). As suggested by the clustering of $U$. delphinus versus $U$. foucauldianus specimens in the scatter plot, PC1 and PC2 values were significantly different between these two species as well as between the ten populations (ANOVAs, factor 'species'; response variable 'PC1': $F=262.8, d f=1, p<0.0001$; response variable 'PC2': $F=62.3, d f=1, p<0.0001$; factor 'population'; response variable 'PC1': $d f=9, F=41.2, p<0.0001$; response variable 'PC2': $d f=9, F=10.55, p<0.0001)$. As illustrated by synthetic outlines of extreme shell forms, PC1 represents a trend from a triangular to trapezoidal shell shape, and PC2 represents a trend from a straight ventral margin and well-developed, protruding dorso-posterior margin to a weak, sloping dorsoposterior margin and a concavely shaped posterior part of the ventral margin (Fig. 4).

The two species differed significantly in their sagittal shell shape. Tukey's post hoc comparisons revealed significant differences in PC1 values between all populations from different species, with $U$. delphinus and $U$. foucauldianus typically featuring a triangular and trapezoidal sagittal outline, respectively (Table S3; Fig. 4). Interspecific patterns in PC2 values were less consistent. The high degree of morphological divergence of $U$. delphinus and $U$. foucauldianus was also confirmed by DFA on the 18 Fourier coefficients, which classified $95 \%$ of specimens to the correct species (Hotelling's $\left.T^{2}=861.83, F=45.004, p<0.0001\right)$.

\section{Microsatellites}

All ten loci were successfully combined in two multiplexed PCRs and yielded clear and balanced electrophoresis profiles that matched the peaks obtained from single-locus PCRs. The summary of the microsatellite results is given in Table 4. A total of $188 U$. delphinus and $169 U$. foucauldianus alleles were observed across the ten loci, ranging from 14 to 30 (U. delphinus) to 5 to 25 (U. foucauldianus) alleles per locus. Four $U$. delphinus and three $U$. foucauldianus loci deviated from Hardy-Weinberg equilibrium, and generally low positive values of inbreeding coefficients $\left(F_{\text {IS }}\right)$ were found in both species (Table 4).

In $U$. delphinus, null alleles were negligible (Table S4). In U. foucauldianus, one locus, i.e. UD3, showed significant null alleles presence values (Table S4). However, this locus was not excluded from subsequent analyses, as its removal affected neither the $F_{\text {ST }}$ values nor the final population structure results (data not shown). Linkage disequilibrium was not detected, indicating that all the new loci can be considered as 
Table 1 Mean genetic divergence for the COI dataset, between Unio delphinus and Unio foucauldianus

\begin{tabular}{llllllllll}
\hline & U. delphinus & PInf & PolyS & Number of individuals & $h$ & Hd \pm SD & $\pi \pm$ SD & Fu's Fs & Tajima's D \\
\hline U. delphinus & & 9 & 21 & 56 & 15 & $0.860 \pm 0.023$ & $0.00465 \pm 0.0024$ & $-3.567^{*}$ & -1.08111 \\
U. foucauldianus & 0.032 & 2 & 2 & 19 & 4 & $0.520 \pm 0.123$ & $0.00100 \pm 0.00068$ & -1.093 & 0.24790
\end{tabular}

The number of base differences per site from averaging over all sequence pairs between the species are shown

PInf parsimony informative sites, Poly $S$ polymorphic sites, $h$ haplotypes, $H d \pm S D$ haplotype diversity, $\pi \pm S D$ nucleotide diversity

${ }^{*} p<0.05$, statistically significant values; tests of population growth within each species, i.e. the results of Fu's Fs and Tajima's D neutrality tests

independent markers. Population microsatellite statistics are shown in Table 2. Within $U$. delphinus, three populations were not in Hardy-Weinberg equilibrium and generally most showed low levels of significant $F_{\text {IS }}$. Three of the four analysed $U$. foucauldianus populations were not in Hardy-Weinberg equilibrium, and all showed low levels of significant $F_{\text {IS. }}$. Pairwise $F_{\text {ST }}$ values for both species were all significant after sequential Bonferroni correction, indicating moderate genetic differentiation among all populations (data not shown).

The plots of $\Delta K$ based on the STRUCTURE analyses indicated that two $(K=2)$ is the most likely number of clusters present in the entire dataset (Fig. 2, middle). For the $U$. delphinus dataset, only two clusters were revealed (Fig. 2, right top A): one included the populations from the Minho in the North to the Tejo in the South, whereas the other included the populations from the Southern Iberia, i.e. Guadiana, Guadalquivir and Barbate. Two additional runs were made for each of these clusters. The first was then subdivided in $2(K=2)$, where the Minho population stands alone (Fig. 2, right top B); whereas the most likely number of clusters present in the second was three $(K=3)$, corresponding to each of the three populations analysed (Fig. 2, right top C). For the $U$. foucauldianus dataset, three $(\mathrm{K}=3)$ is the most likely number of clusters present: the two Northern Morocco populations cluster together (Mda and Sebou) and the other two (Oum-Er-Rbia and Noun) are separated (Fig. 2, right below).

Wilcoxon signed-rank tests revealed no evidence of recent bottleneck events, as the tests were not significant for heterozygosity excess in all populations for both species. Moreover, the mode-shift indicator test revealed an L-shaped pattern of allele frequencies, supporting the absence of a recent bottleneck in both species.

\section{Discussion}

In an effort to clarify the phylogeny of the pictorum lineage, as well as the distribution of the species in Iberia and Maghreb, and the role of the MSC as a vicariant event, we sequenced the
COI gene fragment, assessed shell morphometry patterns and genotyped microsatellites in individuals across both regions.

\section{Phylogeny, taxonomy, morphometry and distribution}

The phylogenetic analysis presented in this study revealed two exclusively monophyletic allopatric lineages separated by the Gibraltar Strait, here recognised as two distinct species, i.e. U. delphinus inhabiting the western basins of Iberia (from the Ulla in the North to the Guadalhorce in the South; Fig. 1) and $U$. foucauldianus only present in the Atlantic Moroccan basins (from Mharhar in the North to the Noun in the South; Fig. 1). Two voucher specimens per species were deposited at the Museu Nacional de História Natural e da Ciência, Lisboa, Portugal (U. foucauldianus: MB28-004382 and MB28004383; U. delphinus: MB28-004384 and MB28-004385). $U$. delphinus and $U$. foucauldianus belong to the pictorum lineage, with a COI genetic divergence value of $3.2 \%$ (unc-p distance) between each other, which is similar to the values observed between most pairs of recognised Unio sp. within this lineage (Fig. 3; Table 3).

Until the mid-twentieth century, the taxonomy of the genus Unio suffered from an excess of described species due mainly to the high phenotypic plasticity, particularly in shell shape. In this study, and although shell characteristics such as hinge structure and umbo sculpture do not show any distinguishing features (data not shown), shell shape as analysed by Fourier shape analysis was found to be significantly different between $U$. delphinus and $U$. foucauldianus. Overall, the shell outline of $U$. delphinus is more elongated and triangular whereas in $U$. foucauldianus, it is essentially trapezoidal (Fig. 5). The significant differences in shell shape provide additional support for the separation of the two species. Observed variations in shell shape between populations within each species, reflecting considerable phenotypic plasticity, could be attributed to differences in prevailing ecological conditions in the different rivers; a phenomena commonly observed in other freshwater mussel species (Zieritz et al. 2010).

The name and status of $U$. delphinus as a distinct species (separate from U. pictorum) has been considered by Araujo 
Table 2 Summary of indices of genetic diversity estimated from the COI sequencing data for all populations for both species: sample size $(N)$, number of haplotypes $(h)$, haplotype diversity $(\mathrm{Hd})$, nucleotide diversity $(\pi)$

\begin{tabular}{|c|c|c|c|c|c|c|c|c|c|c|c|}
\hline \multirow[t]{2}{*}{ Population } & \multirow[t]{2}{*}{ Species } & \multicolumn{4}{|c|}{$\mathrm{COI}$} & \multicolumn{6}{|c|}{ Microsatellites } \\
\hline & & $N$ & $h$ & Hd & $\pi$ & $N$ & $N_{\mathrm{A}}$ & $H_{\mathrm{E}}$ & $H_{\mathrm{O}}$ & $F_{\text {IS }}$ & HWE \\
\hline 1 & Unio delphinus & 4 & 3 & 0.833 & 0.00158 & 20 & 38 & 0.458 & 0.425 & 0.0983 & $<0.01$ \\
\hline 2 & U. delphinus & 4 & 4 & 1 & 0.00553 & 19 & 84 & 0.785 & 0.769 & 0.0490 & 0.66 \\
\hline 3 & U. delphinus & 3 & 2 & 0.667 & 0.00211 & - & - & - & - & - & - \\
\hline 4 & U. delphinus & 4 & 1 & 0 & 0 & - & - & - & - & - & - \\
\hline 5 & U. delphinus & 4 & 1 & 0 & 0 & 18 & 73 & 0.740 & 0.783 & -0.0294 & 0.89 \\
\hline 6 & U. delphinus & 3 & 1 & 0 & 0 & 19 & 81 & 0.699 & 0.742 & -0.0340 & 0.63 \\
\hline 7 & U. delphinus & 4 & 2 & 0.5 & 0.00158 & 18 & 82 & 0.735 & 0.733 & 0.0305 & 0.23 \\
\hline 8 & U. delphinus & 4 & 2 & 0.667 & 0.00105 & - & - & - & - & - & - \\
\hline 9 & U. delphinus & 4 & 2 & 0.667 & 0.00211 & - & - & - & - & - & - \\
\hline 10 & U. delphinus & 3 & 1 & 0 & 0 & - & - & - & - & - & - \\
\hline 11 & U. delphinus & 4 & 2 & 0.5 & 0.00079 & 19 & 123 & 0.837 & 0.768 & 0.1088 & $<0.01$ \\
\hline 12 & U. delphinus & 4 & 2 & 0.5 & 0.00079 & - & - & - & - & - & - \\
\hline 13 & U. delphinus & 2 & 2 & 1 & 0.00158 & - & - & - & - & - & - \\
\hline 14 & U. delphinus & 4 & 3 & 0.833 & 0.00237 & 20 & 85 & 0.712 & 0.690 & 0.0558 & 0.04 \\
\hline 15 & U. delphinus & 4 & 2 & 0.5 & 0.00079 & 20 & 97 & 0.748 & 0.640 & 0.1691 & $<0.01$ \\
\hline 16 & U. delphinus & 1 & 1 & 0 & 0 & - & - & - & - & - & \\
\hline 17 & U. foucauldianus & 3 & 2 & 0.667 & 0.00105 & 20 & 124 & 0.801 & 0.780 & 0.0512 & $<0.01$ \\
\hline 18 & U. foucauldianus & 4 & 2 & 0.667 & 0.00105 & 19 & 115 & 0.799 & 0.790 & 0.0386 & $<0.01$ \\
\hline 19 & U. foucauldianus & 4 & 1 & 0 & 0 & 19 & 73 & 0.653 & 0.542 & 0.1953 & $<0.01$ \\
\hline 20 & U. foucauldianus & 4 & 2 & 0.5 & 0.00079 & 20 & 52 & 0.545 & 0.550 & 0.0162 & 0.14 \\
\hline 21 & U. foucauldianus & 4 & 1 & 0 & 0 & - & - & - & - & - & - \\
\hline
\end{tabular}

From microsatellites genotyping: sample size $(N)$, number of alleles $\left(N_{\mathrm{A}}\right)$, expected heterozygosity $\left(H_{\mathrm{E}}\right)$, observed heterozygosity $\left(H_{\mathrm{O}}\right)$, inbreeding coefficient $\left(F_{\mathrm{IS}}\right)$, and Hardy-Weinberg equilibrium exact test $p$ value (HWE). Population numbers follow Fig. 1 and Table S1

et al. (2009a) and U. foucauldianus has been synonymized with $U$. gibbus by Araujo et al. (2009b). However, this taxonomic situation is further complicated by the fact that several Unio species names have been published from the Atlantic basins of Morocco. Most of these (e.g. Unio ksibianus Mousson 1874, Unio martelli Pallary 1918 and Unio rhomboideus Moquin-Tandon 1855) were later synonymized with Potomida littoralis (Cuvier 1798) (Haas 1969), the most widespread unionid species in North Africa. Of the two remaining Unio names available, Unio tifleticus Pallary 1923 should be considered as a junior synonym of $U$. gibbus, as proposed by Araujo et al. 2009a, while U. foucauldianus is here recognised not as $U$. gibbus but as the valid name for the other Unio species found in Morocco, since its original description and plates match the specimens from the present study. Pallary first described this species in 1936 from specimens collected at the Ait Melloul bridge, in the lower section of the Sous River, which now dries completely in the summer and where the species has not been recorded for decades. Unfortunately, the present location of the type specimens of $U$. foucauldianus is unknown.

\section{Role of messinian salinity crisis as a vicariant and calibration event}

Information collected in this study strongly indicates that the land bridge, which originated during the MSC, was the corridor allowing the migration of the genus Unio into North Africa. The earlier point in time of the radiation of $U$. delphinus in comparison with that of $U$. foucauldianus may be attributed to the fact that the climatic fluctuations in Iberia do not reach the levels of desiccation that characterise the humid-arid cycles in North Africa (Le Houérou 1992), thus providing a more stable riverine network and less genetic drift. The effect of the relatively small sample size for North Africa in this respect cannot be ruled out but is unlikely to play a major role given the extent of the sampled area. To confirm this would require sampling of nuclear genes or the male mitochondria, given the presented mtDNA data only reflects the history of the maternal lineage.

The obtained molecular rate for female-type COI $(0.27$ $\pm 0.06 \% / \mathrm{my}$ ) using the MSC as a calibration event is the first and only estimated for the Unionida order to date. 


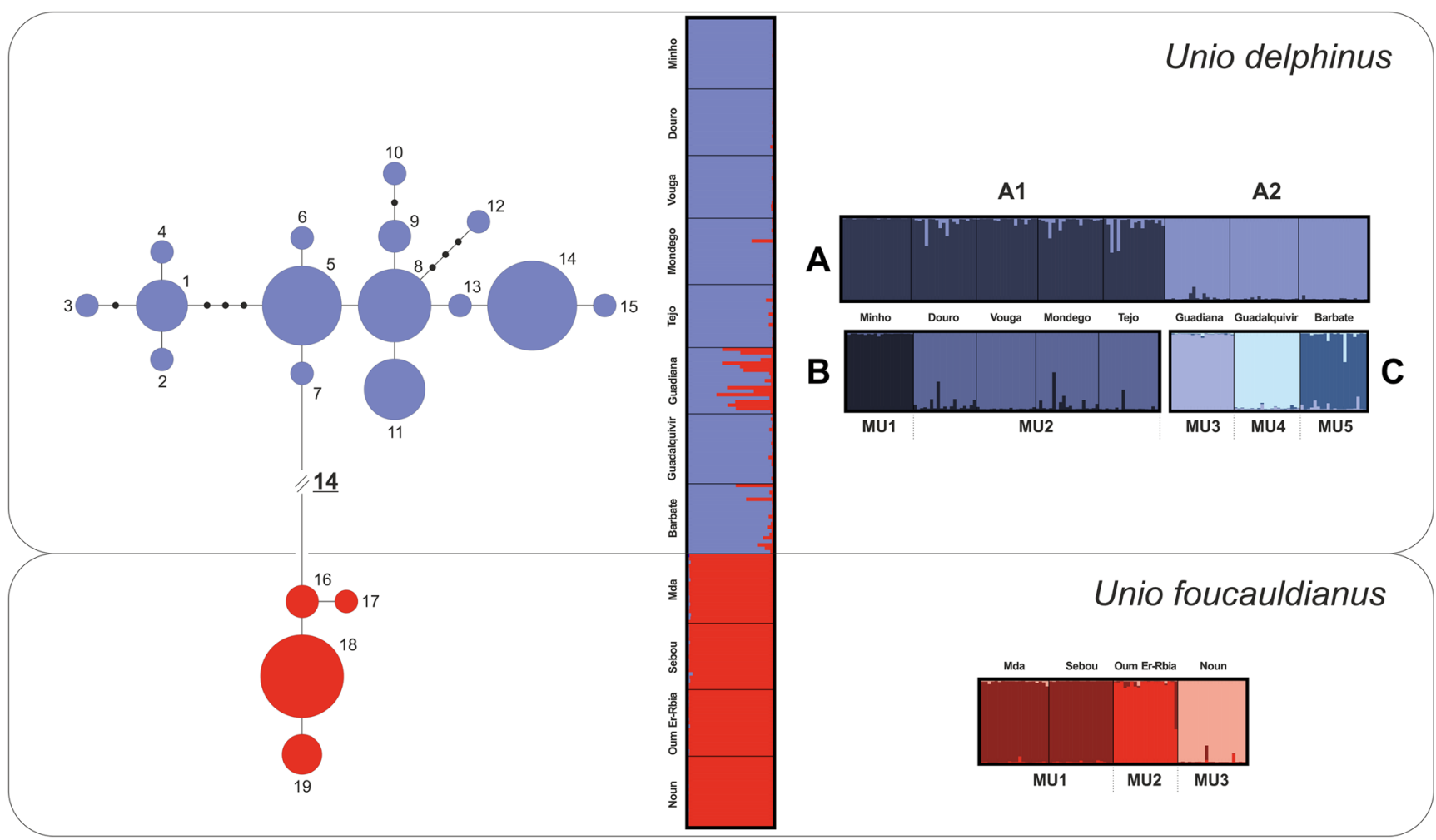

Fig. 2 Left, haplotype (TCS) networks showing the relationships of Unio delphinus (blue) and Unio foucauldianus (red) specimens, inferred from the same individuals sequenced for the COI mtDNA (Table S1, Supporting information). Circle size is proportional to the observed haplotype frequencies, and black points represent unobserved haplotypes and potential intermediates. Middle, STRUCTURE analyses when using all populations for both species $(K=2)$. Upper right, STRUCTURE analyses in $U$. delphinus for $\mathbf{A} K=2$, using all populations; B $K=2$, for populations in cluster A1; and $\mathbf{C} K=3$, for populations in cluster A2. Right below, STRUCTURE analyses in $U$. foucauldianus for $K=3$ (using all populations). Each individual is represented by a vertical bar in $K$-coloured segments with the length of each bar being proportional to the estimated membership coefficient. Black lines separate individuals from different geographic regions (see Fig. 1; Table S1, Supporting information, for population codes). The programmes CLUMPP v.1.1.2 (Jakobsson and Rosenberg 2007) and DISTRUCT v.1.1 (Rosenberg 2004) were used to graphically display individual's membership coefficients for each cluster
Surprisingly, this rate is much slower than those published for other bivalves (e.g. $0.6 \%$ /my in Renard et al. 2000; Mock et al. 2010; 0.67-1.21\%/my in Marko 2002; and 0.55$2.04 \%$ /my in Luttikhuizen et al. 2003). Due to this difference, future studies on Unionida should use the rate obtained in this study instead.

\section{Phylogeography and population genetics}

This first assessment on the population genetic structure and demographic history of $U$. delphinus and $U$. foucauldianus across their entire distributions greatly increased the almost non-existent available data on these taxa and revealed unexpected patterns. Within $U$. delphinus, there was only one supported mtDNA cluster that was geographically concordant, i.e. the Southernmost Iberian River basins: Guadalquivir, Barbate and Guadiaro. On the other hand, mtDNA analysis of $U$. foucauldianus did not reveal the existence of any geographically concordant sub-clades. Although this might be influenced by the low number of sampled populations, the wide range of the collected basins support the reported pattern. The lack of geographic concordance of the mtDNA clusters were unexpected, especially for the Iberian $U$. delphinus, as a recent phylogeographic study on another freshwater mussel species, Anodonta anatina (Linnaeus 1758), revealed a complex phylogeographic history and the presence of several divergent mtDNA lineages within the Iberian range (Froufe et al. 2014).

The tests of demographic history (for COI mtDNA) suggested a recent demographic expansion within $U$. delphinus as did the low levels of significant $F_{\text {IS }}$ obtained in most populations (microsatellites). The results of the same tests obtained for $U$. foucauldianus were incongruent most likely due to the low number of individuals analysed.

Habitat loss and fragmentation have important consequences for population persistence by reducing dispersal, connectivity and population size (Brook et al. 2008). Here, we applied ten newly developed microsatellite loci to characterise patterns of population genetic structure and test for the genetic signature of the population declines in order to provide key 


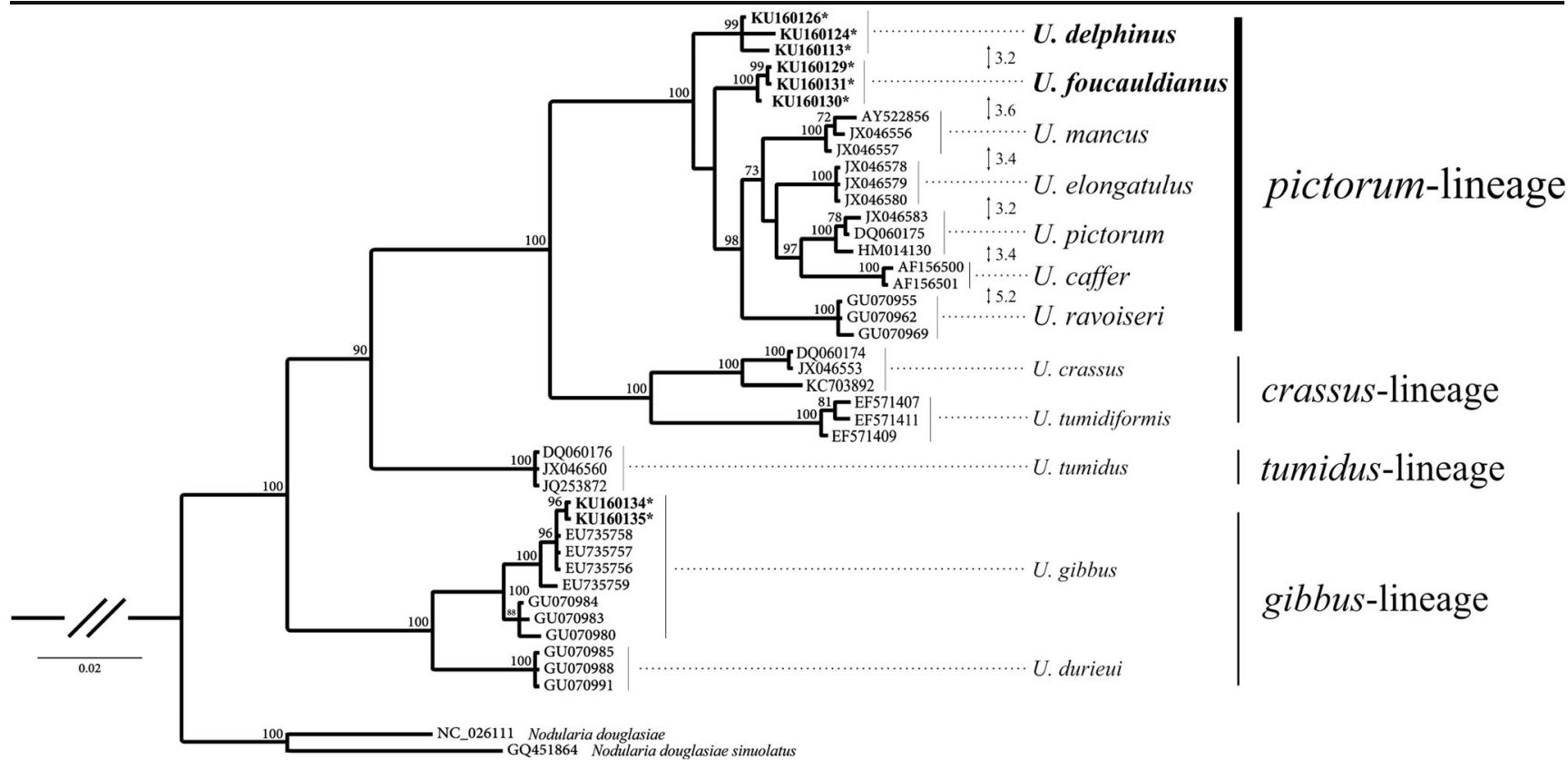

Fig. 3 Phylogenetic tree obtained by Bayesian Inference analysis of the COI fragment using one model for each codon position: 1st (HKY), 2nd (F81) and 3rd (GTR +I). Support values are given as Bayesian posterior probability above nodes. The tree was rooted with Nodularia douglasiae.
Numerical values among the species names refer to uncorrected $p$ distance values between the respective clades, inside the pictorum lineage. See Table 3 and Table S2 for detailed information

the lower sections of the Oum Er-Rbia basin. This range contraction is likely due to the strong effects of dams, agriculture and water extraction (Sousa et al. 2016).

The most likely number of clusters from the microsatellite Bayesian assignment analysis indicates a strong genetic structure within $U$. delphinus and $U$. foucauldianus populations. In $U$. delphinus, a major division is seen between the northern and southern basins. The northern range is further divided into two clusters, with the Minho population appearing isolated from the others. On the other hand, the southern Iberian basins seem to belong to three independent clusters. As for $U$. foucauldianus, the two northern populations cluster together, and the others correspond to two additional genetic pools each. In this context, several distinct management units (MUs) were identified for each species, since they present a high among-population differentiation, mainly at the nuclear loci
Table 3 Pairwise genetic F-COI gene fragment distance matrix (unc. $p$-distance) of the pictorum lineage (below the diagonal); standard deviation (above the diagonal)

\begin{tabular}{llllllll}
\hline & $\begin{array}{l}\text { Unio } \\
\text { caffer }\end{array}$ & $\begin{array}{l}\text { Unio } \\
\text { mancus }\end{array}$ & $\begin{array}{l}\text { Unio } \\
\text { delphinus }\end{array}$ & $\begin{array}{l}\text { Unio } \\
\text { foucauldianus }\end{array}$ & $\begin{array}{l}\text { Unio } \\
\text { ravoisieri }\end{array}$ & $\begin{array}{l}\text { Unio } \\
\text { elongatulus }\end{array}$ & $\begin{array}{l}\text { Unio } \\
\text { pictorum }\end{array}$ \\
\hline U. caffer & & 0.008 & 0.008 & 0.008 & 0.009 & 0.008 & 0.007 \\
U. mancus & 0.047 & & 0.007 & 0.007 & 0.008 & 0.007 & 0.007 \\
U. delphinus & 0.050 & 0.039 & & 0.007 & 0.008 & 0.008 & 0.008 \\
U. foucauldianus & 0.047 & 0.036 & 0.032 & & 0.008 & 0.008 & 0.008 \\
U. ravoisieri & 0.052 & 0.045 & 0.048 & 0.042 & & 0.008 & 0.008 \\
U. elongatulus & 0.042 & 0.034 & 0.045 & 0.037 & 0.046 & & 0.007 \\
U. pictorum & 0.034 & 0.034 & 0.043 & 0.040 & 0.045 & 0.032 & \\
\hline
\end{tabular}


Fig. 4 Unio delphinus (white symbols) and Unio foucauldianus (black and grey symbols) shell outline principal component scores for the first two PC axes obtained on 18 Fourier coefficients. Synthetic shell outlines of 'extreme' morphotypes are displayed with the anterior margin facing to the left and the dorsal margin to the top of the page. For population information, please see Fig. 1 and Table S1, Supporting information

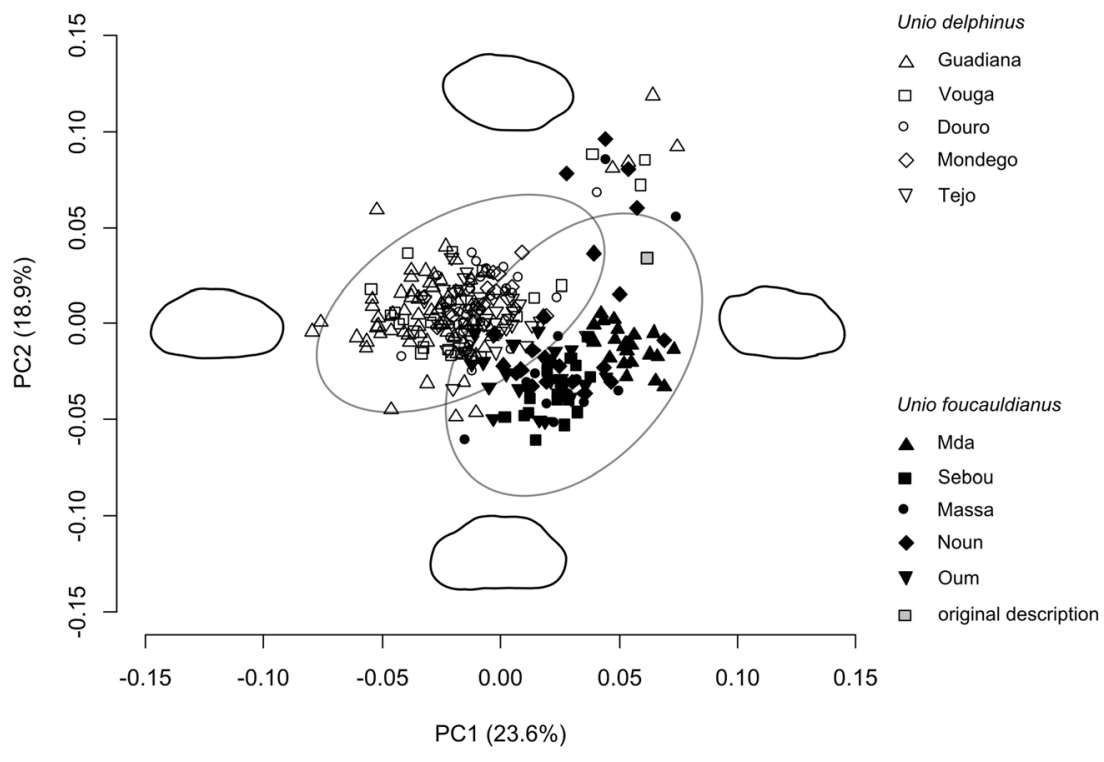

(Hedrick et al. 2001; Caballero et al. 2012). U. delphinus was divided in five MUs. The first restricted to the Minho basin (MU1, Fig. 2 upper right), the second encompassing all basins between the Douro and the Tejo (MU2, Fig. 2, upper right) and the last three within each of the main southern Iberian basins Guadiana, Guadalquivir and Barbate (MU3, MU4 and MU5; Fig. 2, upper right). U. delphinus has been recently assessed as near threatened by the IUCN (Araujo 2011b) due

Table 4 Characteristics of 10 polymorphic microsatellite loci in Unio delphinus and Unio foucauldianus

\begin{tabular}{|c|c|c|c|c|c|c|c|c|c|c|}
\hline Locus & Primer sequences $\left(5^{\prime}-3^{\prime}\right)$ & $\begin{array}{l}\text { Fluorescent } \\
\text { dye }\end{array}$ & Repeat & $N_{\mathrm{A}}$ & $\begin{array}{l}\text { Allele size } \\
\text { range (bp) }\end{array}$ & $H_{\mathrm{E}}$ & $H_{\mathrm{O}}$ & $F_{\text {IS }}$ & HWE & $\begin{array}{l}\text { GenBank } \\
\text { accession }\end{array}$ \\
\hline \multicolumn{11}{|l|}{ MixA } \\
\hline UD2 & $\begin{array}{l}\text { F: ACATTGCAAACAACGTAGCG } \\
\text { R: CATGCGAATGGGTATTATCG }\end{array}$ & VIC & $(\mathrm{ac})_{18}$ & $\begin{array}{l}19 \\
22\end{array}$ & $\begin{array}{l}126-164 \\
130-176\end{array}$ & $\begin{array}{l}0.63 \\
0.77\end{array}$ & $\begin{array}{l}0.61 \\
0.74\end{array}$ & $\begin{array}{l}0.02 \\
0.04\end{array}$ & $\begin{array}{l}0.72 \\
0.39\end{array}$ & KU131298 \\
\hline UD3 & $\begin{array}{l}\text { F: AGGTTCAGCAGATTCGCTTG } \\
\text { R: AACCAACCAGCCAAGCATAC }\end{array}$ & PET & $(\operatorname{atgt})_{13}$ & $\begin{array}{l}16 \\
20\end{array}$ & $\begin{array}{l}153-213 \\
173-253\end{array}$ & $\begin{array}{l}0.77 \\
0.76\end{array}$ & $\begin{array}{l}0.73 \\
0.46\end{array}$ & $\begin{array}{l}0.06 \\
0.39\end{array}$ & $\begin{array}{r}0.26 \\
<0.01\end{array}$ & KU131299 \\
\hline UD8 & $\begin{array}{l}\text { F: ACTGCGGATCTTTCAGATGT } \\
\text { R: CAGTGACGGTAGGTAGGTTGG }\end{array}$ & NED & $(\text { acat })_{8}$ & $\begin{array}{l}17 \\
25\end{array}$ & $\begin{array}{l}200-264 \\
208-308\end{array}$ & $\begin{array}{l}0.80 \\
0.87\end{array}$ & $\begin{array}{l}0.80 \\
0.70\end{array}$ & $\begin{array}{l}0.00 \\
0.19\end{array}$ & $\begin{array}{l}<0.01 \\
<0.01\end{array}$ & KU131300 \\
\hline UD21 & $\begin{array}{l}\text { F: TCTCGAACTTTATTCGTGATGTAG } \\
\text { R: ACGTGCGTGACGATCACTAT }\end{array}$ & PET & $(\mathrm{gt})_{17}$ & $\begin{array}{l}20 \\
13\end{array}$ & $\begin{array}{l}266-306 \\
280-304\end{array}$ & $\begin{array}{l}0.76 \\
0.76\end{array}$ & $\begin{array}{l}0.70 \\
0.78\end{array}$ & $\begin{array}{r}0.08 \\
-0.04\end{array}$ & $\begin{array}{l}0.17 \\
0.31\end{array}$ & KU131303 \\
\hline UD24 & $\begin{array}{l}\text { F: CGTAGAACGATGGGAAGGAA } \\
\text { R: ACATGTAGCATACATACTGAGTTGC }\end{array}$ & FAM & $(\text { tgta })_{13}$ & $\begin{array}{l}30 \\
21\end{array}$ & $\begin{array}{l}313-445 \\
341-449\end{array}$ & $\begin{array}{l}0.88 \\
0.86\end{array}$ & $\begin{array}{l}0.80 \\
0.71\end{array}$ & $\begin{array}{l}0.09 \\
0.17\end{array}$ & $\begin{array}{l}<0.01 \\
<0.01\end{array}$ & KU131304 \\
\hline UD28 & $\begin{array}{l}\text { F: TTCGTAATGGCAAATGGACA } \\
\text { R: AGACCTGAGGAGGACGCATA }\end{array}$ & VIC & $(\mathrm{ca})_{14}$ & $\begin{array}{l}18 \\
24\end{array}$ & $\begin{array}{l}193-233 \\
207-269\end{array}$ & $\begin{array}{l}0.70 \\
0.81\end{array}$ & $\begin{array}{l}0.72 \\
0.78\end{array}$ & $\begin{array}{r}-0.02 \\
0.03\end{array}$ & $\begin{array}{l}0.54 \\
0.02\end{array}$ & KU131305 \\
\hline UD29 & $\begin{array}{l}\text { F: TTGCACTGGAATTAAATTTAGGGT } \\
\text { R: TGCCGTTTATTTGGACAATAC }\end{array}$ & NED & $(\mathrm{ac})_{13}$ & $\begin{array}{l}18 \\
12\end{array}$ & $\begin{array}{l}114-152 \\
118-140\end{array}$ & $\begin{array}{l}0.65 \\
0.65\end{array}$ & $\begin{array}{l}0.57 \\
0.68\end{array}$ & $\begin{array}{r}0.13 \\
-0.05\end{array}$ & $\begin{array}{r}<0.01 \\
0.87\end{array}$ & KU131306 \\
\hline UD31 & $\begin{array}{l}\text { F: ACCAAACAAATTGTGAGGGA } \\
\text { R: GAGAACATAATTCAAATAACGTGAGTG }\end{array}$ & FAM & $(\operatorname{tg})_{12}$ & $\begin{array}{r}14 \\
5\end{array}$ & $\begin{array}{l}179-207 \\
179-189\end{array}$ & $\begin{array}{l}0.59 \\
0.22\end{array}$ & $\begin{array}{l}0.57 \\
0.23\end{array}$ & $\begin{array}{r}0.04 \\
-0.04\end{array}$ & $\begin{array}{l}0.17 \\
1.00\end{array}$ & KU131307 \\
\hline \multicolumn{11}{|l|}{ MixB } \\
\hline UD15 & $\begin{array}{l}\text { F: ATCACCCATGACTGCGAAAT } \\
\text { R: GCTGCATAGACAAATTACGAACA }\end{array}$ & FAM & (cata) $)_{18}$ & $\begin{array}{l}21 \\
17\end{array}$ & $\begin{array}{l}134-214 \\
146-230\end{array}$ & $\begin{array}{l}0.86 \\
0.84\end{array}$ & $\begin{array}{l}0.86 \\
0.90\end{array}$ & $\begin{array}{r}0.00 \\
-0.07\end{array}$ & $\begin{array}{l}0.33 \\
0.20\end{array}$ & KU131301 \\
\hline UD19 & $\begin{array}{l}\text { F: TCATGGTGCTTGTTTTAATTCTTG } \\
\text { R: AGTTCAACGTCTCGGTGAAAA }\end{array}$ & NED & $(\operatorname{tag})_{16}$ & $\begin{array}{l}15 \\
10\end{array}$ & $\begin{array}{l}207-252 \\
216-258\end{array}$ & $\begin{array}{l}0.73 \\
0.65\end{array}$ & $\begin{array}{l}0.59 \\
0.66\end{array}$ & $\begin{array}{r}0.19 \\
-0.01\end{array}$ & $\begin{array}{r}<0.01 \\
0.21\end{array}$ & KU131302 \\
\hline
\end{tabular}

Primer sequences (forward primer sequence $(\mathrm{F})$, reverse primer sequence $(\mathrm{R})$ ); fluorescent dyes; repeat motif; and GenBank accession references. For the remaining columns, the upper values set in italics correspond to $U$. delphinus and the lower values to $U$. foucauldianus: number of observed alleles per locus $\left(N_{\mathrm{A}}\right)$; sizes of amplified fragments; mean expected heterozygosity $\left(H_{\mathrm{E}}\right)$; mean observed heterozygosity $\left(H_{\mathrm{O}}\right)$; inbreeding coefficient $\left(F_{\mathrm{IS}}\right)$; HardyWeinberg deviation (HWE; $P$ ) 
Fig. 5 Left, shell pictures of representative Unio delphinus specimens (a River Guadiana, b River Mondego) and corresponding synthetic outline for the average shell shape (c). Right, shell pictures of representative Unio foucauldianus specimens (d River Mda, e River Noun) and corresponding synthetic outline for the average shell shape (f)

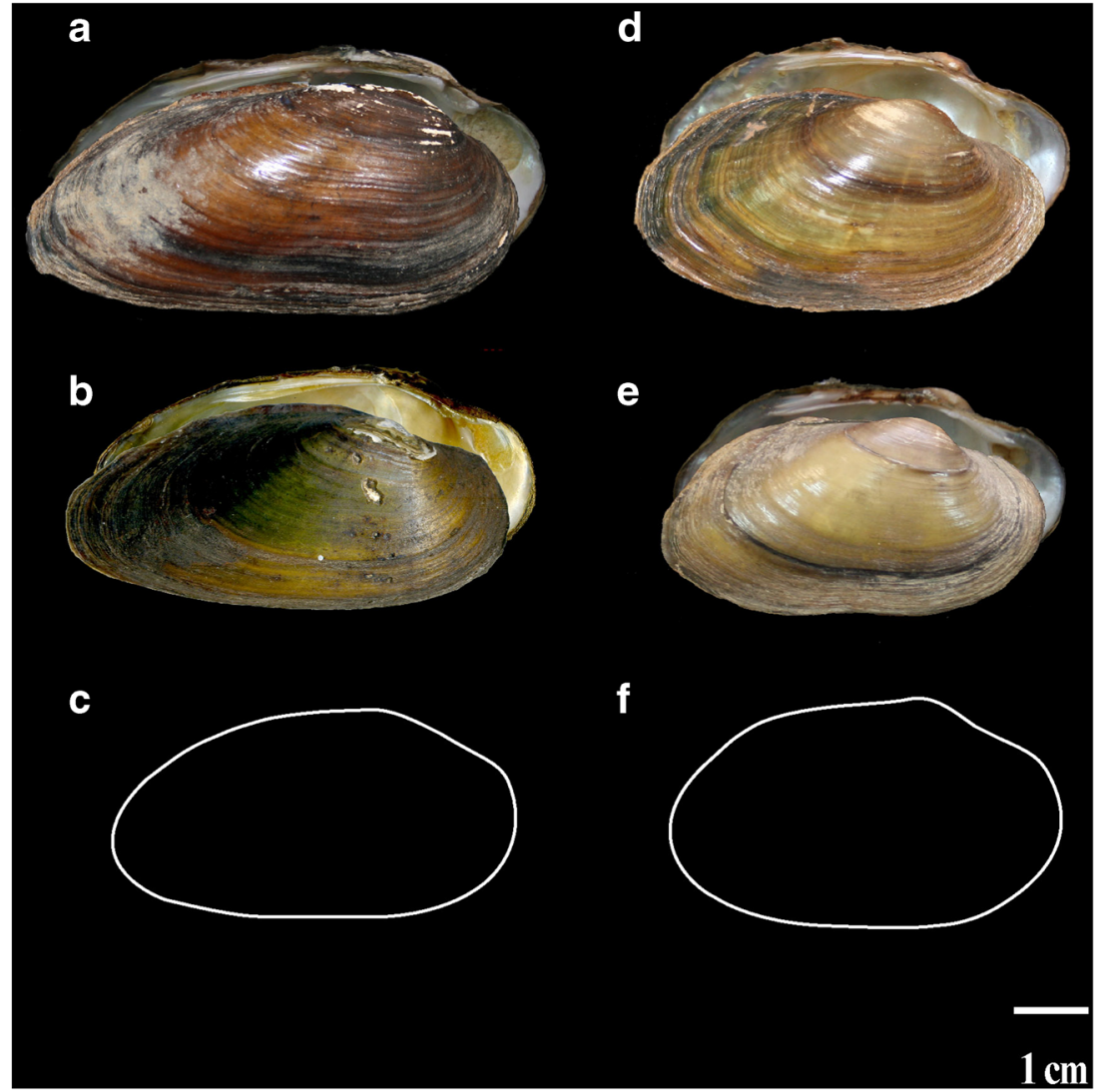

to a generalised decline in the number of populations and individuals; thus, the Minho and Southern Iberian MUs should receive a special consideration due to their restricted distributions. The presence of dams and the impacts generated by invasive species, mainly of the Asian clam Corbicula fluminea (Müller 1774), are usually described as the main threats to $U$. delphinus in the Minho basin (Sousa et al. 2007, 2008; Novais et al. 2016). Also, special care should be addressed to the populations in the South where besides the negative impacts of dams and pollution, water resources are scarce due to overexploitation for human consumption (Company et al. 2008).

Our study presents the first in depth analysis of the molecular and morphological diversity of the critically endangered U. foucauldianus (IUCN; Van Damme and Ghamizi 2010). Three MUs were detected: one encompassing the northern populations of the Mda and Sebou basins (MU1, Fig. 2, below right), and the other two within each of the southern basins, Oum-Er-Rbia (MU2) and Noun (MU3) (Fig. 2, below right). The present conservation status of the species should be revised and probably down-listed, since its actual range is much wider than previously evaluated (Van Damme and Ghamizi 2010). In addition, at several sites, the species attained a high density (authors' personal observation). On the other hand, the $U$. foucauldianus MUs identified in the present study indicate that the species requires special conservation attention, especially with regard to the southern Noun and Oum-erRbia populations. The Noun is an intermittent river where the population only remain in small pools in the lower sections of the river. As for the Oum-Er-Rbia, although it is one of the major basins in Morocco, a high percentage of its water is being presently extracted for irrigation. This has led to summer desiccation of some of the smaller tributaries and a lower water level of the main channel where the species is mainly restricted to the lower section (Sousa et al. 2016). The increase of the human population with subsequent urban and agriculture development as well as future climate change projections pose a serious threat to these mussel populations in south Morocco.

\section{Conclusions and future directions}

This study has delivered important information about the phylogenetic and phylogeographical processes of post-glacial colonisation patterns freshwater taxa across the western Mediterranean. The estimated molecular rate reported herein represents the first for the Unionida and will serve as a crucial tool for future studies of this kind. By providing another piece of evidence to understand the main processes that have shaped the biodiversity of this important geographic area, we also point out the value of investigating diversity with multiple marker systems (molecular and morphological). Future 
research should seek to compare these results with other freshwater bivalve species inhabiting the same area, particularly those with different ecological traits, i.e. with different modes of reproduction and in different habitat types. Investigating understudied regions of North Africa can be particularly useful for the understanding of the evolutionary dynamics of the Unio species as well as freshwater mussels in general and also aid in our long-term goal of systematic revision of the genus. Finally, the newly developed microsatellite loci applied here for the first time, should be tested and used for the other related Unio species, especially within the pictorum lineage, for which these markers are still not available.

Acknowledgements The authors wish to thank the two anonymous reviewers for helpful remarks and suggestions that improved the quality of the manuscript. Financial support was provided by Portuguese Foundation for Science and Technology (FCT) project PTDC/AAC-AMB/ 117688/2010 and by Mohamed bin Zayed Species Conservation Fund (reference 15256799). Official capture and sampling licenses were issued by the following agencies: (1) Junta de Castilla y León (Consejería de Fomento y Medio Ambiente EP/CYL/331/2012, de 17 de Abril de 2012); (2) Junta de Andalucia (Consejería de Medio Ambiente-SGYB/FOA/ AFR/SFS, de 17 de Julio de 2012); and (3) Université Cadi Ayyad (Faculté des Sciences, Semlalia, Marrakech, Maroc).

\section{References}

Appleton, C. C. (1996). Freshwater mollusks of southern Africa, with a chapter on bilharzia and its snail hosts. Pietermaritzburg: University of Natal Press. 64 pp.

Araujo, R. (2011a). Unio gibbus. In IUCN red list of threatened species 2011: e.T171953A6812362. Accessed 15 Oct 2015.

Araujo, R. (2011b). Unio delphinus. In IUCN red list of threatened species. Version 2015.3. Available at http://www.iucnredlist.org/. Accessed 15 Oct 2015.

Araujo, R. (2011c). Unio delphinus. In IUCN red list of threatened species 2011: e.T195510A8975648. doi:10.2305/IUCN.UK.2011-2. RLTS.T195510A8975648.en. Accessed 08 Nov 2015.

Araujo, R., Gómez, I., \& Machordom, A. (2005). The identity and biology of Unio mancus ( $=$ U. elongatulus) (Bivalvia: Unionidae) in the Iberian Peninsula. Journal of Molluscan Studies, 71, 25-31.

Araujo, R., Reis, J., Machordom, A., Toledo, C., Madeira, M. J., Gómez, I., Velasco, J. C., Morales, J., Barea, J. M., Ondina, P., \& Ayala, I. (2009a). The naiades of the Iberian Peninsula. Iberus, 27, 7-72.

Araujo, R., Toledo, C., \& Machordom, A. (2009b). Redescription of Unio gibbus Spengler, 1793, a west palaearctic freshwater mussel with hookless glochidia. Malacologia, 51, 131-141.

Belkhir, K., Borsa, P., Chikhi, L., Raufaste, N., \& Bonhomme, F. (2004). GENETIX 4.05, population genetics software for Windows TM. Montpellier: Université de Montpellier II.

Breton, S., Beaupre, H. D., Stewart, D. T., Hoeh, W. R., \& Blier, P. U. (2007). The unusual system of doubly uniparental inheritance of mtDNA: isn't one enough? Trends in Genetics, 23, 465-474.

Brook, B. W., Sodhi, N. S., \& Bradshaw, C. J. A. (2008). Synergies among extinction drivers under global change. Trends in Ecology and Evolution, 25, 453-460.

Caballero, S., Islas-Villanueva, V., Tezanos-Pinto, G., Duchene, S., Delgado-Estrella, A., Sanchez-Okrucky, R., \& MignucciGiannoni, A. A. (2012). Phylogeography, genetic diversity and population structure of common bottlenose dolphins in the Wider
Caribbean inferred from analyses of mitochondrial DNA control region sequences and microsatellite loci: conservation and management implications. Animal Conservation, 15, 95-112.

Carranza, S., Arnold, E. N., \& Pleguezuelos, J. M. (2006). Phylogeny, biogeography, and evolution of two Mediterranean snakes, Malpolon monspessulanus and Hemorrhois hippocrepis (Squamata, Colubridae), using mtDNA sequences. Molecular Phylogenetics and Evolution, 40, 532-546.

Chapuis, M. P., \& Estoup, A. (2007). Microsatellite null alleles and estimation of population differentiation. Molecular Biology and Evolution, 24, 621-631.

Clement, M., Posada, D., \& Crandall, K. A. (2000). TCS: a computer program to estimate gene genealogies. Molecular Ecology, 9, 1657.

Company, R., Serafim, A., Lopes, B., Cravo, A., Shepherd, T. J., Pearson, G., \& Bebianno, M. J. (2008). Using biochemical and isotope geochemistry to understand the environmental and public health implications of lead pollution in the lower Guadiana River, Iberia: a freshwater bivalve study. Science of the Total Environment, 405, 109-119.

Crampton, J. S., \& Haines, A. J. (1996). Users' manual for programs HANGLE, HMATCH and HCURVE for the Fourier shape analysis of two-dimensional outlines. Institute of Geological and Nuclear Sciences Science Report, 96, 1-28.

Cuttelod, A., Seddon, M. B., \& Neubert, E. (2011). European red list of non-marine molluscs. Luxembourg: Publications Office of the European Union.

Di Rienzo, A., Peterson, A. C., Garcza, J. C., Valdes, A. M., Slatkin, M., \& Freimer, N. B. (1994). Mutational processes of simple-sequence repeat loci in human populations. Proceedings of the National Academy of Sciences of the United States of America, 91, 31663170.

Drummond, A. J., \& Rambaut, A. (2007). BEAST: Bayesian evolutionary analysis by sampling trees. BMC Evolutionary Biology, 7, 214.

Drummond, A. J., Ho, S. Y., Phillips, M. J., \& Rambaut, A. (2006). Relaxed phylogenetics and dating with confidence. PLoS Biology, 4, 699 .

Earl, D. A., \& Von Holdt, B. M. (2012). Structure harvester: a website and program for visualizing STRUCTURE output and implementing the Evanno method. Conservation Genetics Resources, 4, 359-361.

Evanno, G., Regnaut, S., \& Goudet, J. (2005). Detecting the number of clusters of individuals using the software STRUCTURE: a simulation study. Molecular Ecology, 14, 2611-2620.

Fonseca, M. M., Brito, J. C., Paulo, O. S., Carretero, M. A., \& Harris, D. J. (2009). Systematic and phylogeographical assessment of the Acanthodactylus erythrurus group (Reptilia: Lacertidae) based on phylogenetic analyses of mitochondrial and nuclear DNA. Molecular Phylogenetics and Evolution, 51, 131-142.

Froufe, E., Sobral, C., Teixeira, A., Lopes, A., Sousa, R., Varandas, S., \& Lopes-Lima, M. (2013). Development and multiplexing of microsatellite loci for the near threatened freshwater mussel Potomida littoralis (Cuvier, 1798) using 454 sequencing. Aquatic Conservation: Marine and Freshwater Ecosystems, 23, 619-623.

Froufe, E., Sobral, C., Teixeira, A., Lopes, A., Sousa, R., Varandas, S., Aldridge, D. C., \& Lopes-Lima, M. (2014). Genetic diversity of the pan-European freshwater mussel Anodonta anatina (Bivalvia: Unionoida) based on COI: new insights on the genus phylogeny and implications for its conservation. Aquatic Conservation: Marine and Freshwater Ecosystems, 24, 561-574.

Froufe, E., Gan, H. M., Lee, Y. P., Carneiro, J., Varandas, S., Teixeira, A., Zieritz, A., Sousa, R., \& Lopes-Lima. (2016). The Male and Female complete mitochondrial genome sequences of the Endangered Freshwater Mussel Potomida littoralis, (Cuvier, 1798) (Bivalvia: Unionidae). mtDNA Journal. doi:10.3109/19401736.2015. 1074223.

García-París, M., Alcobendas, M., Buckley, D., \& Wake, D. B. (2003). Dispersal of viviparity across contact zones in Iberian populations of 
fire salamanders (Salamandra) inferred from discordance of genetic and morphological traits. Evolution, 57, 129-143.

Gaubert, P., Machordom, A., Morales, A., López-Bao, J. V., Veron, G., Amin, M., Barros, T., Basuony, M., Djagoun, C. A. M. S., Do Linh San, E., Fonseca, C., Geffen, E., Ozkurt, S. O., Cruaud, C., Couloux, A., \& Palomares, F. (2010). Comparative phylogeography of two African carnivorans presumably introduced into Europe: disentangling natural versus human-mediated dispersal across the Strait of Gibraltar. Journal of Biogeography, 38, 341-358.

Gómez, A., \& Lunt, D. H. (2007). Refugia within refugia: patterns of phylogeographic concordance in the Iberian Peninsula. In S. Weiss \& N. Ferrand (Eds.), Phylogeography in southern European refugia: evolutionary perspectives on the origin and conservation of European biodiversity (pp. 155-188). Dordrecht: Springer.

Goudet, J. (1995). FSTAT: a computer program to calculate F-statistics. Journal of Heredity, 86, 485-486.

Graf, D. L. (2007). Palearctic freshwater mussel (Mollusca: Bivalvia: Unionoida) diversity and the Comparatory Method as a species concept. Proceedings of the Academy of Natural Sciences of Philadelphia, 156, 71-88.

Graf, D. L., \& Cummings, K. S. (2007). Review of the systematics and global diversity of freshwater mussel species (Bivalvia: Unionoida). Journal of Molluscan Studies, 73, 291-314.

Graf, D. L., \& Cummings, K. S. (2015). The freshwater mussels (Unionoida) of the world (and other less consequential bivalves) In MUSSEL Project. Available at http://mussel-project.uwsp.edu/. Accessed 1 Aug 2015.

Haas, F. (1969). Superfamilia Unionacea. Das Tierreich Vol. 88. De Gruyter, Berlin. [in German].

Hall, T. A. (1999). BioEdit: a user-friendly biological sequence alignment editor and analysis program for Windows 95/98/NT. Nuclear Acids Symposium Series, 41, 95-98.

Hammer, Ø., \& Harper, D. A. T. (2006). PAST, Version 1.57. Available at: http://folk.uio.no/ohammer/past/.

Hedrick, P. W., Parker, K. M., \& Lee, R. N. (2001). Using microsatellite and MHC variation to identify species, ESUs, and MUs in the endangered Sonoran topminnow. Molecular Ecology, 10, 1399-1412.

Hoeh, W. R., Stewart, D. T., Sutherland, B. W., \& Zouros, E. (1996). Multiple origins of gender-associated mitochondrial DNA lineages in bivalves (Mollusca: Bivalvia). Evolution, 50, 2276-2286.

Holm, S. (1979). A simple sequentially rejective multiple test procedure. Scandinavian Journal of Statistics, 6, 65-70.

Huang, X. C., Rong, J., Liu, Y., Zhang, M. H., Wan, Y., Ouyang, S., Zhou, C. H., \& Wu, X. P. (2013). The complete maternally and paternally inherited mitochondrial genomes of the endangered freshwater mussel Solenaia carinatus (Bivalvia: Unionidae) and implications for Unionidae taxonomy. PloS One, 8, e84352.

Husemann, M., Ray, J. W., King, R. S., Hooser, E. A., \& Danley, P. D. (2012). Comparative biogeography reveals differences in population genetic structure of five species of stream fishes. Biological Journal of the Linnean Society, 107, 867-885.

Jakobsson, M., \& Rosenberg, N. A. (2007). CLUMPP: a cluster matching and permutation program for dealing with label switching and multimodality in analysis of population structure. Bioinformatics, 23, 1801-1806

Khalloufi, N., \& Boumaïza, M. (2009). First record and biology of Unio gibbus Spengler, 1793 in Tunisia. Biologia, 64, 1-6.

Khalloufi, N., Toledo, C., Machordom, A., Boumaïza, M., \& Araújo, R. (2011). The unionids of Tunisia: Taxonomy and phylogenetic relationships, with redescription of Unio ravoisieri (Deshayes, 1847) and U. durieui (Deshayes, 1847). Journal of Molluscan Studies, 77, 103-115.

Kingman, J. (1982). The coalescent. Stochastic Processes and Their Applications, 13, 235-248.
Krijgsman, W., Hilgen, F. J., Raffi, I., Sierro, F. J., \& Wilson, D. S. (1999). Chronology, causes and progression of the Messinian salinity crisis. Nature, 400, 652-655.

Kristensen, T. K., Stensgaard, A-S., \& Appleton, C. (2010). In IUCN Red List of Threatened Species. Version 2015.3. Available at http://www. iucnredlist.org/. Accessed 15 Oct 2015.

Le Houérou, H. N. (1992). Vegetation and land use in the Mediterranean basin by the year 2050: a prospective study. Climatic Change and the Mediterranean, 1, 175-232.

Li, W. H. (1997). Molecular evolution. Sunderland: Sinauer. 432 pp.

Liu, H. P., Mitton, J. B., \& Wu, S. K. (1996). Paternal mitochondrial DNA differentiation far exceeds maternal mitochondrial DNA and allozyme differentiation in the freshwater mussel, Anodonta grandis grandis. Evolution, 50, 952-957.

Lopes-Lima, M., Teixeira, A., Froufe, E., Lopes, A., Varandas, S., \& Sousa, R. (2014). Biology and conservation of freshwater bivalves: past, present and future perspectives. Hydrobiologia, 735, 1-13.

Lopes-Lima, M., Sousa, R., Teixeira, A., Varandas, S., Riccardi, N., Aldridge, D. C., \& Froufe, E. (2016a). Newly developed microsatellite markers for the pan-European duck mussel, Anodonta anatina: revisiting the main mitochondrial lineages. Aquatic Conservation: Marine and Freshwater Ecosystems. doi:10.1002/aqc.2575. Published online (19 Jun 2015) in Wiley Online Library.

Lopes-Lima, M., Sousa, R., Geist, J., Aldridge, D., Araujo, R., Bergengren, J., Bespalaja, Y., Bodis, E., Burlakova, L., Van Damme, D., Douda, K., Froufe, E., Georgiev, D., Gumpinger, C., Karatayev, A., Kebapci, U., Killeen, I., Lajtner, J., Larsen, B., Lauceri, R, Legakis, A., Lois, S., Lundberg, S., Moorkens, E., Motte, G., Nagel, K-O., Ondina, P., Outeiro, A., Paunovic, M., Prié, V., Von Proschwitz, T., Riccardi, N., Rudzīte, M., Rudzītis, M., Scheder, C., Seddon, M., Sereflisan, H., Simić, V., Sokolova, S., Stoeckl, K., Taskinen, J., Teixeira, A., Thielen, F. Trichkova, T., Varandas, S., Vicentini, H., Zajac, K., Zajac, T. \& Zogaris, S. (2016b). Conservation Status of Freshwater Mussels in Europe: state of the art and future challenges. Biological Reviews. doi:10.1111/ brv.12244. Published online (4 Jan 2016) in Wiley Online Library.

Luikart, G., Allendorf, F. W., Cornuet, J. M., \& Sherwin, W. B. (1998). Distortion of allele frequency distributions provides a test for recent population bottlenecks. Journal of Heredity, 89, 238-247.

Luttikhuizen, P. C., Drent, J., \& Baker, A. J. (2003). Disjunct distribution of highly diverged mitochondrial lineage clade and population subdivision in a marine bivalve with pelagic larval dispersal. Molecular Ecology, 12, 2215-2229.

Machordom, A., Araujo, R., Toledo, C., Zouros, E., \& Ladoukakis, E. D. (2015). Female-dependent transmission of paternal mtDNA is a shared feature of bivalve species with doubly uniparental inheritance (DUI) of mitochondrial DNA. Journal of Zoological Systematics and Evolutionary Research, 53, 200-204.

Malausa, T., Gilles, A., Meglécz, E., Blanquart, H., Duthoy, S., Costedoat, C., Dubut, V., Pech, N., Castagnone-Sereno, P., Délye, C., Feau, N., Frey, P., Gauthier, P., Guillemaud, T., Hazard, L., Le Corre, V., Lung-Escarmant, B., Malé, P. J., Ferreira, S., \& Martin, J. F. (2011). High-throughput microsatellite isolation through 454 GSFLX Titanium pyrosequencing of enriched DNA libraries. Molecular Ecology Resources, 11, 638-644.

Marko, P. B. (2002). Fossil calibration of molecular clocks and the divergence times of geminate species pairs separated by the Isthmus of Panama. Molecular Biology and Evolution, 19, 2005-2021.

Miraldo, A., Hewitt, G. M., Paulo, O. S., \& Emerson, B. C. (2011). Phylogeography and demographic history of Lacerta lepida in the Iberian Peninsula: multiple refugia, range expansions and secondary contact zones. BMC Evolutionary Biology, 11, 170.

Mock, K. E., Brim Box, J. C., Chong, J. P., Howard, J. K., Nez, D. A., Wolf, D., \& Gardner, R. S. (2010). Genetic structuring in the freshwater mussel Anodonta corresponds with major hydrologic basins in the western United States. Molecular Ecology, 19, 569-591. 
Morais, P., Rufino, M. M., Reis, J., Dias, E., \& Sousa, R. (2013). Assessing the morphological variability of Unio delphinus Spengler, 1783 (Bivalvia: Unionidae) using geometric morphometry. Journal of Molluscan Studies, 80, 17-23.

Naimo, T. J., Damschen, E. D., Rada, R. G., \& Monroe, E. M. (1998). Nonlethal evaluation of the physiological health of unionid mussels: methods for biopsy and glycogen analysis. Journal of the North American Benthological Society, 17, 121-128.

Novais, A., Dias, E., \& Sousa, R. (2016). Inter and intraspecific variation of carbon and nitrogen stable isotopes ratios in freshwater bivalves. Hydrobiologia, 765, 149-158.

Ortmann, A. E. (1912). Notes upon the families and genera of the najades. Annals of the Carnegie Museum, 8, 222-365.

Piry, S., Luikart, G., \& Cornuet, J. M. (1999). BOTTLENECK: a computer program for detecting recent reductions in the effective population size using allele frequency data. Journal of Heredity, 90, 502 503.

Plazzi, F., \& Passamonti, M. (2010). Towards a molecular phylogeny of Mollusks: Bivalves' early evolution as revealed by mitochondrial genes. Molecular Phylogenetics and Evolution, 57, 641-657.

Posada, D. (2008). JModelTest: phylogenetic model averaging. Molecular Biology and Evolution, 25, 1253-1256.

Prié, V., \& Puillandre, N. (2014). Molecular phylogeny, taxonomy, and distribution of French Unio species (Bivalvia, Unionidae). Hydrobiologia, 735, 95-110.

Prié, V., Puillandre, N., \& Bouchet, P. (2012). Bad taxonomy can kill: molecular reevaluation of Unio mancus Lamarck, 1819 (Bivalvia: Unionidae) and its accepted subspecies. Knowledge and Management of Aquatic Ecosystems, 405, 08.

Pritchard, J. K., Stephens, M., \& Donnelly, P. (2000). Inference of population structure using multilocus genotype data. Genetics, 155, 945-959.

Rambaut, A., Suchard, M. A., Xie, D., \& Drummond, A. J. (2014). Tracer v1.6, Available from http://beast.bio.ed.ac.uk/Tracer.

Ramos-Onsins, S. E., \& Rozas, J. (2002). Statistical properties of new neutrality tests against population growth. Molecular Biology and Evolution, 12, 2092-2100.

Rasband, W. (2008). ImageJ. Image processing and analysis in Java. Bethesda, MD: National Institutes of Health, USA. Available from http://rsbweb.nih.gov/ij.

Raymond, M., \& Rousset, F. (1995). GENEPOP (version 1.2): population genetics software for exact tests and ecumenicism. Journal of Heredity, 86, 248-249.

Reis, J., Machordom, A., \& Araujo, R. (2013). Morphological and molecular diversity of unionidae (Mollusca, Bivalvia) from Portugal. Graellsia, 69, 17-36.

Renard, E., Bachmann, V., Cariou, M. L., \& Moreteau, C. (2000). Morphological and molecular differentiation of invasive freshwater species of the genus Corbicula (Bivalvia, Corbiculidea) suggest the presence of three taxa in French rivers. Molecular Ecology, 9, 20092016.

Riccardi, N., Froufe, E., Lopes-Lima, M., \& Mazzoli, C. (2016). When and how? Freshwater mussel recolonization in Lake Orta? Journal of Limnology (Accepted, 2015).

Ronquist, F., Teslenko, M., van der Mark, P., Ayres, D. L., Darling, A., Höhna, S., Larget, B., Liu, L., Suchard, M. A., \& Huelsenbeck, J. P. (2012). MrBayes 3.2: efficient Bayesian phylogenetic inference and model choice across a large model space. Systematic Biology, 61, 539-542.

Rosenberg, N. A. (2004). DISTRUCT: a program for the graphical display of population structure. Molecular Ecology Notes, 4, 137-138.

Sambrook, J., Fritsch, E. F., \& Maniatis, T. (1989). Molecular cloning: a laboratory manual. New York: Cold Harbor Spring Press.

Schmitt, T., Hewitt, G. M., \& Müller, P. (2006). Disjunct distributions during glacial and interglacial periods in mountain butterflies: Erebia epiphron as an example. Journal of Evolutionary Biology, 19, 108-113.
Sousa, R., Antunes, C., \& Guilhermino, L. (2007). Species composition and monthly variation of the Molluscan fauna in the freshwater subtidal area of the River Minho estuary. Estuarine, Coastal and Shelf Science, 75, 90-100.

Sousa, R., Dias, S., Guilhermino, L., \& Antunes, C. (2008). Minho River tidal freshwater wetlands: threats to faunal biodiversity. Aquatic Biology, 3, 237-250.

Sousa, R., Varandas, S., Teixeira, A., Ghamizi, M., Froufe, E., \& LopesLima, M. (2016). Pearl mussels (Margaritifera marocana) in Morocco: conservation status of the rarest bivalve in African fresh waters. Science of the Total Environment, 547, 405-412.

Steinfartz, S., Veith, M., \& Tautz, D. (2000). Mitochondrial sequence analysis of Salamandra taxa suggests old splits of major lineages and postglacial recolonizations of Central Europe from distinct source populations of Salamandra salamandra. Molecular Ecology, 9, 397-410.

Strayer, D. L. (2008). Freshwater mussel ecology: a multifactor approach to distribution and abundance. London: University of California Press.

Strayer, D. L., Downing, J. A., Haag, W. R., King, T. L., Layzer, J. B., Newton, T. J., \& Nichols, S. J. (2004). Changing perspectives on pearly mussels, North America's most imperilled animals. BioScience, 54, 429-439.

Tamura, K., Stecher, G., Peterson, D., Filipski, A., \& Kumar, S. (2013). MEGA6: molecular evolutionary genetics analysis version 6.0. Molecular Biology and Evolution, 30, 2725-2729.

Van Damme, D. (1984). The freshwater Mollusca of northern Africa: distribution, biogeography and palaeoecology. Dordrecht: Dr. W. Junk Publishers. 164 pp.

Van Damme, D. (2011). Unio pictorum. In IUCN Red List of Threatened Species. Version 2015.3. Available from http://www.iucnredlist.org/. Accessed 15 Oct 2015.

Van Damme, \& Ghamizi. (2010). Unio foucauldianus. In IUCN Red List of Threatened Species. Version 2015.3. Available from http://www. iucnredlist.org/. Accessed 15 Oct 2015.

Van Oosterhout, C., Hutchinson, W. F., Wills, D. P., \& Shipley, P. (2004). MICRO-CHECKER: software for identifying and correcting genotyping errors in microsatellite data. Molecular Ecology Notes, 4, 535-538.

Walker, J. M., Curole, J. P., Wade, D. E., Chapman, E. G., Bogan, A. E., \& Watters, G. T. (2006). Taxonomic distribution and phylogenetic utility of gender-associated mitochondrial genomes in the Unionoida (Bivalvia). Malacologia, 48, 265-282.

Walker, J. M., Bogan, A. E., Bonfiglio, E. A., Campbell, D. C., Christian, A. D., Curole, J. P., Harris, J. L., Wojtecki, R. J., \& Hoeh, W. R. (2007). Primers for amplifying the hypervariable, male-transmitted COII-COI junction region in amblemine freshwater mussels (Bivalvia: Unionoidea: Ambleminae). Molecular Ecology Notes, 7, 489-491.

Weir, B. S., \& Cockerham, C. C. (1984). Estimating $F$-statistics for the analysis of population structure. Evolution, 38, 1358-1370.

Zieritz, A., \& Aldridge, D. C. (2009). Identification of ecophenotypic trends within three European freshwater mussel species (Bivalvia: Unionoida) using traditional and modern morphometric techniques. Biological Journal of the Linnean Society, 98, 814-825.

Zieritz, A., Hoffman, J. I., Amos, H. W., \& Aldridge, D. C. (2010). Phenotypic plasticity and genetic isolation-by-distance in the freshwater mussel Unio pictorum (Mollusca: Unionidae). Evolutionary Ecology, 24, 923-938.

Zouros, E., Ball, A. O., Saavedra, C., \& Freeman, K. R. (1994a). Mitochondrial DNA inheritance. Nature, 368, 8-18.

Zouros, E., Ball, A. O., Saavedra, C., \& Freeman, K. R. (1994b). An unusual type of mitochondrial DNA inheritance in the blue mussel Mytilus. Proceedings of the National Academy of Sciences of the United States of America, 91, 7463-7467. 